\title{
DISCRIMINAÇÃO DE SOROVARES DE Salmonella spp. ISOLADOS DE CARCAÇAS DE FRANGO POR REP E ERIC-PCR E FAGOTIPAGEM DO SOROVAR ENTERIDITIS ${ }^{1}$
}

\author{
Iliana ALCOCER 2 , Kelly Mari P. DE OLIVEIRA ${ }^{3}$, Marilda Carlos VIDOTTO ${ }^{4}$, \\ Tereza Cristina R.M. de OLIVEIRA ${ }^{5, *}$
}

\begin{abstract}
RESUMO
Salmonelose é a infecção bacteriana de origem alimentar mais freqüente no Paraná, Brasil, e os surtos estão associados, principalmente, ao consumo de ovos, carne de aves e derivados. Os objetivos deste trabalho foram identificar os sorovares de Salmonella isolados de carcaças de frango e caracterizá-los molecularmente por REP e ERIC-PCR, assim como identificar os fagotipos de Salmonella Enteriditis. Dos 25 isolados de Salmonella spp. analisados, 18 foram identificados como Enteriditis, 4 como Braenderup, 2 como Worthington e 1 como infantis. Dos 18 isolados de Enteriditis, 14 foram PT4, 2 PT4a, 1 PT7 e 1 RDNC, por se tratar de colônia rugosa. REP-PCR forneceu padrão eletroforético distinto de 10 a 13 bandas distribuídas entre 120 e 2072 pb para cada sorovar diferente testado. A ERIC-PCR mostrou um padrão de 4 a 5 bandas entre 180 e 1000 pb e foi menos discriminativa quando comparada à REP-PCR. Os resultados encontrados confirmaram que a fagotipagem é uma ferramenta útil e discriminativa para o sorovar Enteriditis. Apesar do pequeno número de sorovares testados, os resultados sugerem que a REP-PCR parece ser um método atrativo a ser utilizado no futuro para a discriminação preliminar de sorovares de Salmonella.

Palavras-chaves: Salmonella Enteriditis, fagotipos, sorovar, REP-PCR, ERIC-PCR.
\end{abstract}

\section{SUMMARY}

DISCRIMINATION OF Salmonella SEROVARS ISOLATED FROM CHICKEN MEAT BY REP AND ERIC-PCR AND PHAGOTYPING OF Enteriditis SOROVAR. Salmonellosis is the most prevalent bacterial food-borne disease in the State of Paraná, Brazil, and the outbreaks are often associated with consumption of poultry products. The aim of this study was to serotype Salmonella strains isolated from chicken carcasses and characterize them molecularly using REP and ERIC-PCR. The phage types of Salmonella Enteriditis were also identified. Of the 25 Salmonella strains analysed, 18 were identified as Enteriditis, 4 as Braenderup, 2 as Worthington and 1 as infantis. Of the 18 Enteriditis isolates, 14 were PT4, 2 PT4a, 1 PT7 and 1 "reacted, but did not conform" - RDNC. Distinct REP-PCR profiles with 10 to 13 fragments distributed between 120 and 2072 pb were easily obtained for each serovar tested. ERIC-PCR showed patterns of 4 to 5 fragments between 180 and 1000 pb and less discriminatory power than REPPCR. The results confirmed that phage typing is a useful tool to differentiate into sorovar Enteriditis. Although it is recognized that only a limited number of strains was tested in this study, the results suggest that REP-PCR could be an attractive choice to be used in the future as a preliminary method of Salmonella sorovar discrimination.

Keywords: Salmonella Enteriditis, phage type, serotypes, REP-PCR, ERIC-PCR

\section{1 - INTRODUÇÃO}

O Brasil iniciou sua produção intensiva de aves na década de 60 e atualmente é o segundo maior produtor e o primeiro exportador mundial de carne de frango [29], sendo o Paraná o maior produtor e exportador do Brasil. Em 2004 , a produção foi de aproximadamente 8,409 milhões de toneladas com $29,7 \%$ deste total exportado. O consumo per capita passou de 2,3 kg, em 1971, para 34,6 kg, em 2002, tornando-se o Brasil o quarto maior consumidor de carne de frango no mundo [2].

\footnotetext{
${ }^{1}$ Recebido para publicação em 4/8/2005. Aceito para publicação em 28/4/2005 (001586)

${ }^{2}$ Pontificia Universidad Católica del Ecuador, Facultad de Ciencias Exactas y Naturales, Escuela de Ciencias Biológicas, Av. 12 de Octubre, 1.076 y Carrión, Apartado 17-01-2184, Quito - Ecuador

${ }^{3}$ Centro Universitário de Maringá, Avenida Guedner, 1.610, Jardim Aclimação, CEP 87050-390 - Maringá (PR), Brasil

${ }^{4}$ Universidade Estadual de Londrina, Centro de Ciências Biológicas, Departamento de Microbiologia, Campus Universitário, Caixa Postal 6001, CEP 87051-970 - Londrina (PR), Brasil

${ }^{5}$ Universidade Estadual de Londrina, Centro de Ciências Agrárias, Departamento de Tecnologia de Alimentos e Medicamentos, Campus Universitário, Caixa Postal 6001, CEP 87051-970 - Londrina (PR), Brasil

E-mail: tereza@uel.br

*A quem a correspondência deve ser enviada
}

Em vários países, o aumento de casos esporádicos e de surtos de salmonelose humana está relacionado com o aumento da infecção por Salmonella Enteriditis devido ao consumo de carne de aves, ovos e derivados contaminados. Estudos mostram que a ocorrência de Salmonella spp. em carcaça de frango pode variar de 0,024\% a 85,0\%, sendo um veículo importante de transmissão dessa bactéria [18].

No Paraná, a partir de 1995, a salmonelose passou a ser a principal doença transmitida por alimentos. Entre 1999 e 2002, 91 surtos de salmonelose foram registrados no Laboratório Central de Saúde Pública Estadual (Lacen), Curitiba, Paraná. Os ovos e derivados foram responsáveis por 52,5\% desses surtos, seguidos pelo bolo (30,0\%), maionese $(22,5 \%)$ e carnes (35,3\%) [1]. O envolvimento de mais de um alimento contaminado por surto mostrou a importância da contaminação cruzada na epidemiologia desta doença.

Embora em vários países o aumento da incidência de samonelose devido ao aumento da infecção por Salmonella entérica subsp. entérica sorovar enteriditis ( $S$. Enteriditis) esteja relacionado com o consumo de produtos de origem avícola contaminados, os fagotipos (PT) prevalentes não são os mesmos nos diferentes países [10]. Um predomínio do PT4 tem sido observado na Europa, especialmente na 
Inglaterra, assim como no Brasil [25]. Nos Estados Unidos, o PT8 e PT13a são os mais freqüentes [7, 19, 35, 36].

Entre os métodos moleculares utilizados na caracterização de espécies bacterianas, a amplificação de regiões repetitivas dispersas no genoma dos procariontes localizadas extragenicamente (seqüências repetitivas extragênica palindrômicas - REP) ou intragenicamente (seqüências intergênicas repetitivas consenso enterobacterianas - ERIC) fornecem padrões de bandas distintos e característicos, os quais têm sido utilizados na análise genética, filogenética e taxonômica, e em estudos epidemiológicos [5, 4, 28].

VERSALOVIC, KOEUTH \& LUPSKI [31] determinaram, através da reação em cadeia da polimerase (PCR), a presença de seqüências REP e ERIC distribuídas no genoma das eubactérias. Apesar da grande homologia das seqüências REP e ERIC entre as enterobactérias, DIMRI et al. [12] observaram uma variação em quantidade e localização destes elementos no genoma de E. coli, Shigella, Salmonella, Klebsiella, Enterobacter, Serratia, Erwinia e Proteus. A REP e ERIC são métodos simples, rápidos e sensíveis que podem ser utilizados para discriminar sorovares relacionados [4, 20, 31, 34].

A caracterização dos sorovares de Salmonella isolados no Paraná, que é o maior produtor de carne de frango do Brasil, contribuirá para um melhor controle e prevenção da salmonelose, doença de origem alimentar mais freqüente nesse Estado.

Os objetivos deste trabalho foram identificar os sorovares de Salmonella isolados de carcaças de frango e caracterizálos molecularmente empregando a REP e ERIC-PCR, assim como identificar os fagotipos de Salmonella Enteriditis.

\section{2 - MATERIAL E MÉTODOS}

\section{1 - Isolados bacterianos}

Vinte e cinco amostras de Salmonella isoladas de carcaças de frango entre outubro de 1999 e março de 2000, provenientes de quatro diferentes abatedouros foram analisadas neste trabalho.

Salmonella enteriditis IAL 1132 adquirida no Instituto Adolfo Lutz São Paulo, SP e Escherichia coli HB 101 foram usadas como controles positivo e negativo, respectivamente.

\section{2 - Sorotipagem}

As amostras de Salmonella spp. foram sorotipadas no Laboratório de Enterobactérias do Departamento de Bacteriologia do Instituto Oswaldo Cruz - Fiocruz, do Centro de Referência Nacional de Cólera e outras Enteroinfecções Bacterianas usando aglutinação rápida baseada nas fórmulas antigênicas para Salmonella [24].

As amostras foram mantidas em 1,5 mL de caldo tripticase de soja - TSB (Merck, Darmstadt, Alemanha) com $30 \%$ de glicerol e congelados a $-70^{\circ} \mathrm{C}$ até o uso na caracterização molecular.

\section{3 - Fagotipagem}

As amostras pertencentes ao sorovar enteriditis foram fagotipadas no Instituto Oswaldo Cruz - Fiocruz, de acordo como o descrito por WARD, DE SA \& ROWE [33], empregando 10 fagotipos específicos fornecidos pelo "International Reference Laboratory for Enteric Phage Typing, Colindale", Londres, Inglaterra.

Três a cinco colônias isoladas em ágar nutriente foram transferidas para $3 \mathrm{~mL}$ de caldo fago (caldo nutriente $0,8 \%$ - Difco, Rio de Janeiro, Brasil e cloreto de sódio 0,85\% - Merck) de forma a obter turvação do tubo 1 da Escala de MacFarland. As culturas foram incubadas por $2 \mathrm{~h}$ e $30 \mathrm{~min}$ a $37^{\circ} \mathrm{C}$ em banho-maria com agitação (20rpm) e a turvação padronizada de acordo com os tubos 3 ou 4 da escala de MacFarland. Essas culturas foram semeadas com cotonete na superfície de placas de ágar fago (ágar nutriente 2,8\% - Oxoid, Rio de Janeiro, Brasil; cloreto de sódio 0,35\% - Merck). Após a secagem das placas, foram aplicados $5 \mu \mathrm{L}$ de cada um dos preparados fágicos. As placas foram incubadas a $37^{\circ} \mathrm{C}$ por $18 \mathrm{~h}$.

As áreas de lise foram observadas com uma luz indireta e os resultados interpretados de acordo como os vários graus de lise, segundo o diagrama fornecido pelo "Public Health Laboratory Service - PHLS", Londres, como segue: -, sem lise; + 5 a 20 plaquetas; ++ 21 a 80 ; +++81 a 100; SCL, lise semi-confluente; CL, lise confluente, OL lise opaca.

O padrão de lise de cada cultura foi comparado com aqueles publicados anteriormente. Amostras que foram lisadas por fagos e que não coincidiram com nenhum padrão de lise, foram designadas como reacted, but did not conform $-R D N C$.

\section{4 - Reação em cadeia da polimerase - PCR}

\subsection{1 - Extração de DNA dos isolados}

A extração de DNA seguiu o preconizado por SWANENBURG et al. [27]. As amostras bacterianas foram cultivadas em caldo tripticase soja TSB (Merck) a $37^{\circ} \mathrm{C}$ por $18 \mathrm{~h}$. Alíquotas de 1,5 mL das suspensões bacterianas foram centrifugadas a $16.000 \mathrm{x}$ g por $10 \mathrm{~min}$. O precipitado foi lavado com $900 \mu \mathrm{L}$ de solução salina fisiológica $(0,85 \%)$, centrifugado novamente por $10 \mathrm{~min}$ a 16.000 x g e o precipitado ressuspenso com $500 \mu \mathrm{L}$ de água milliQ estéril. As suspensões foram fervidas a $100^{\circ} \mathrm{C}$ por $10 \mathrm{~min}$, resfriadas em banho de gelo e centrifugadas por 5 mim a 8.100 x g. Para a reação de amplificação foram usados $5 \mu \mathrm{L}$ do sobrenadante diluído em água milliQ. Para a determinação da melhor diluição a ser utilizada, foram testadas inicialmente diluições a 1:5, 1:10, 1:20 e 1:30 em água milliQ do DNA de Salmonella Enteriditis IAL 1132. 


\subsection{2 - Condições da PCR}

Para a reação em cadeia da polimerase foram preparadas soluções de $25 \mu \mathrm{L}$ contendo $12,5 \mu \mathrm{L}$ de tampão duas vezes concentrado preparado com $10 \mathrm{mM}$ Tris pH 8,3, $50 \mathrm{mM}$ $\mathrm{KCl}, 1,5 \mathrm{mM} \mathrm{MgCl} 2$ e $200 \mu \mathrm{M}$ de cada nucleotídeo dNPT (Invitrogen, Life Technology, Brasil), $1 \mu \mathrm{L}$ de cada iniciador (50 pcmol), 1,25 U de Taq polimerase (Invitrogen) e $5 \mu \mathrm{L}$ do DNA. Os iniciadores REP-IRDT (5'-IIINCGNCGNCATCNGGC-3') e REP2-DT (5'-NCGNCTTATCNGGCCTAC-3'), ERIC1R (5'-ATGTAAGCTCCTGGGGATTCAC-3') e ERIC 2 (5'-AAGTAAGTGACTGGGGTGAGCG-3') seqüenciados e testados por VERSALOVIC, KOEUTH \& LUPSKI [31] foram sintetizados pela Gibcobrl, Gaithersburg, MD. Concentrações de $\mathrm{MgCl}_{2}$ variando de 1,5 a 3,5 mM foram testadas.

O material foi amplificado em termociclador Gene Amp PCR System 9700 (Perkin Elmer, Norwalk, CT) com desnaturação a $95^{\circ} \mathrm{C}$ por $5 \mathrm{~min}$, seguida de 40 ciclos a $95^{\circ} \mathrm{C}$ por $1 \mathrm{~min}, 45^{\circ} \mathrm{C}$ por $1 \mathrm{~min}$ e $65^{\circ} \mathrm{C}$ por $8 \mathrm{~min}$ com uma extensão final a $65^{\circ} \mathrm{C}$ por $16 \mathrm{~min}$. Para ERIC-PCR foi programada uma denaturação a $95^{\circ} \mathrm{C}$ por $5 \mathrm{~min}$, seguida de 34 ciclos a $95^{\circ} \mathrm{C}$ por $1 \mathrm{~min}$, anelamento a $52^{\circ} \mathrm{C}$ por 1 min e extensão a $72^{\circ} \mathrm{C}$ por $8 \mathrm{~min}$, com uma extensão final a $72^{\circ} \mathrm{C}$ por $10 \mathrm{~min}$.

\subsection{3 - Análise dos produtos de amplificação}

As amostras contendo o DNA amplificado foram analisadas em gel de agarose 2,0\% (Metaphor ${ }^{\circledR}$ FMC Bioproducts, Rockland, USA). A corrida foi realizada em cuba horizontal de eletroforese Sunrise 192 (Gibco-BRL, Gaithersburg, MD) a 100V/45 mA por $3 \mathrm{~h}$ em tampão borato EDTA (Tris $45 \mathrm{mM}$, ácido bórico, Nuclear, Diadema, Brasil; 45 mM, EDTA 1,25 mM, Merck - TBE). O gel foi corado com brometo de etídeo 25 $\mu \mathrm{g} / \mathrm{mL}$ e visualizado em Image Master VDS 1D Prime (Pharmacia Biotech, San Francisco, CA, USA). Como marcador foi utilizado o DNA de 100 pb (Gibco-BRL, Gaithersburg, MD).

A extração de DNA, a REP-PCR e a eletroforese de todas as amostras foram repetidos duas vezes em dias diferentes.

\subsection{4 - Avaliação dos padrões da PCR}

Os produtos de amplificação foram analisados por exame visual considerando todas as bandas visíveis, independentemente de sua intensidade. O padrão de bandas da REP-PCR foi convertida em uma matriz binária (1, presença; 2, ausência de banda). A porcentagem de similaridade do padrão das bandas foi estimada pelo coeficiente Dice, e a análise de cluster realizada pela média Unweighted Pair Group Method with Arithemetic Averages (UPGMA), gerando dendogramas pelo Sequential Agglomerative Hierarchical and Nested (SAHN) do programa NTSYS - PC 1.7 (Applied Biostatistics, Inc).

\section{3 - RESULTADOS}

\section{1 - Sorotipos e fagotipos de Salmonella}

Dos 25 isolados de Salmonella spp. analisados nesse trabalho, 18 (72,0\%) foram identificados como Enteriditis,
4 (16,0\%) como Braenderup, 2 (8\%) como Worthington e 1 $(4,0 \%)$ como infantis (Tabela 1 ). Dos 18 isolados de Enteriditis, 14 (77,8\%) foram PT4, 2 (11,1\%) PT4a, 1 (5,6\%) PT7 e 1 (5,6\%) RDNC por se tratar de uma colônia rugosa e portanto, sem condições de determinação o fagotipo.

TABELA 1 - Sorovares e fagotipos de Salmonella isolados de diferentes partes de carcaças de frango comercializadas em supermercados de Londrina, Paraná, Brasil entre 1999 e 2000

\begin{tabular}{lcc}
\hline Locais de isolamento & Sorovares & Fagotipos \\
\hline Pele de músculo 1- S-1 & enteriditis & PT4 \\
Pele de pescoço 8-R-1 & enteriditis & PT4 \\
Pele de pescoço 9-R-1 & enteriditis & PT4 \\
Pele de cloaca 9-R-1 & enteriditis & PT4 \\
Embalagem 32-S-1 & enteriditis & PT4a \\
Pele de rim 32-R & enteriditis & PT4a \\
Pele de cloaca 34-R-1 & enteriditis & PT4 \\
Pele de pescoço 39-R-1 & infantis & ND \\
Pele de pescoço 40-R-1 & enteriditis & PT4 \\
Pele de cloaca 52-S-2 & Braenderup & ND \\
Pele de peito 55-R-1 & Braenderup & ND \\
Pele de peito 57-R-2 & Braenderup & ND \\
Rim 58-S-1 & Braenderup & ND \\
Pele de pescoço 58-S-1 & enteriditis & PT4 \\
Pele de cloaca 75-R-1 & enteriditis & PT4 \\
Pele de rim 78-S-2 & Worthington & ND \\
Embalagem 80-R3 & Worthington & ND \\
Pele de pescoço 87-R-2 & enteriditis & PT4 \\
Pele de rim 90-S-1 & enteriditis & PT4 \\
Embalagem 90-R-1 & enteriditis & RDNC \\
Pele de rim 90-R-2 & enteriditis & PT4 \\
Pele de cloaca 91-R-1 & enteriditis & PT7 \\
Pele de cloaca 92-R-1 de cloaca 93-R-2 & enteriditis & PT4 \\
\hline
\end{tabular}

PT - fagotipo; RDNC: reacted, but did not conform; ND - não identificado

\section{2 - Caracterização molecular com REP-PCR}

Os melhores resultados foram obtidos com concentração de $\mathrm{MgCl}_{2}$ de 1,5 mM e DNA extraído por fervura diluído 1:30. As outras diluições testadas não foram reproduzíveis ou produziram um menor número de bandas (dados não apresentados).

A análise eletroforética dos produtos de amplificação gerados pela REP-PCR forneceu um padrão de 10 a 13 bandas distribuídas entre 120 e 2.072 pb .A análise desse padrão revelou a presença de quatro diferentes genótipos, os quais foram agrupados pela análise do dendrograma em quatro grupos 
distintos. Para cada um dos diferentes sorovares, a REP-PCR mostrou um padrão eletroforético único e específico.

A Figura 1 mostra o perfil eletroforético obtido para infantis, Braenderup, Worthington e 11 dos 18 isolados de Enteriditis analisados (Tabela 1). Quatro bandas de aproximadamente 1.500, 700, 570 e 450 pb foram comuns a todos os sorovares. Duas bandas adicionais de 1.350 e $780 \mathrm{pb}$ estavam presentes em quase todos os sorovares. Bandas de 950, 820, 320 e 140 pb foram específicas para Enteriditis, uma banda de 200pb e outra de mais de $2.072 \mathrm{pb}$ foram exclusivas de Braenderup e bandas de 2.072, 790 e 210 pb foram próprias de Worthington. Uma porcentagem de similaridade de $53,5 \%$ e $75,0 \%$ foi encontrada entre os sorovares, os quais foram distribuídos em quatro clusters designados de I a IV. E. coli HB101 está representada no cluster V (Figura 1).

A análise eletroforética dos produtos de amplificação gerados pela ERIC-PCR mostrou um padrão de 4 a 5 bandas distribuídas entre 180 e 1.000 pb. Os resultados obtidos com a ERIC-PCR não foram apresentados e discutidos porque a técnica foi pouco discriminativa quando comparada à REP-PCR.

\section{4 - DISCUSSÃO}

S. Enteriditis tem sido um problema crescente em países com avicultura desenvolvida, particularmente nos Estados Unidos e na União Européia [7], e emergiu como um grande problema avícola e de saúde pública no Brasil a partir de 1993.

Avaliando os dados epidemiológicos de salmonelose no Estado do Paraná entre 1999 a 2004, ALCOCER [1] observou que $89,8 \%$ das cepas de Salmonella isoladas dos alimentos envolvidos nos surtos eram do sorovar Enteriditis.

Embora em vários países a infecção por S. Enteriditis esteja relacionada com o consumo de produtos de origem avícola contaminados, os fagotipos (PT) prevalentes não são os mesmos nos diferentes países (COX, 1995). As aves são consideradas os maiores reservatórios dos fagotipos PT4, 7, 7a, 8, 13, 13a, 23, 24 e 30 [9, 21].

No presente trabalho, foram identificados os fagotipos 4, 4a e 7, sendo o PT4 o lisotipo mais isolado. Dados sobre os fagotipos prevalentes no Brasil são escassos. Porém, PERESI et al. [22] relataram que 100\% das cepas de $S$. Enteriditis isoladas de alimentos e de pacientes envolvidos em 23 surtos ocorridos na região noroeste de São Paulo, entre 1993 e 1997, foram PT4. Esse mesmo fagotipo foi também o mais frequente encontrado por NUNES et al. [21] em 249 amostras de $S$. Enteriditis isoladas de frango, entre 1995 e 1997 no Estado de São Paulo.

No Canadá, o aumento das infecções por S. Enteriditis foi acompanhado pelo aumento significante do isolamento dos fagotipos 4 e 8 . Nesse país, em 1987, apenas duas amostras de $S$. Enteriditis foram identificadas como fagotipo 4 , enquanto que em 1994, o número de isolados foi de 1.000 , o que representou $27 \%$ dos isolados humanos [6].

Outros países relataram aumentos mais dramáticos. Na Inglaterra, por exemplo, entre 1990 e 1996, 50\% dos isolados de S. Enteriditis foram PT4 [23], com 17.371 isolamentos em 1993. A partir de 1997, o número de isolados PT4 diminuiu de 10.056 em 1998 para 2.693 em 2003 [16]. A epidemia de Salmonella Enteriditis no Reino Unido, causada predominantemente pelo PT4, está vinculada a ovos e não à carne de aves. $\mathrm{O}$ ovo contaminado pode ser consumido sem cozimento, o que dificilmente acontece com carne de aves [32].

Uma mudança importante no fagotipo isolado foi observada nos Estados Unidos. Em 1993, os fagotipos mais identificados foram PT8, PT23, PT13 e PT13a porém,

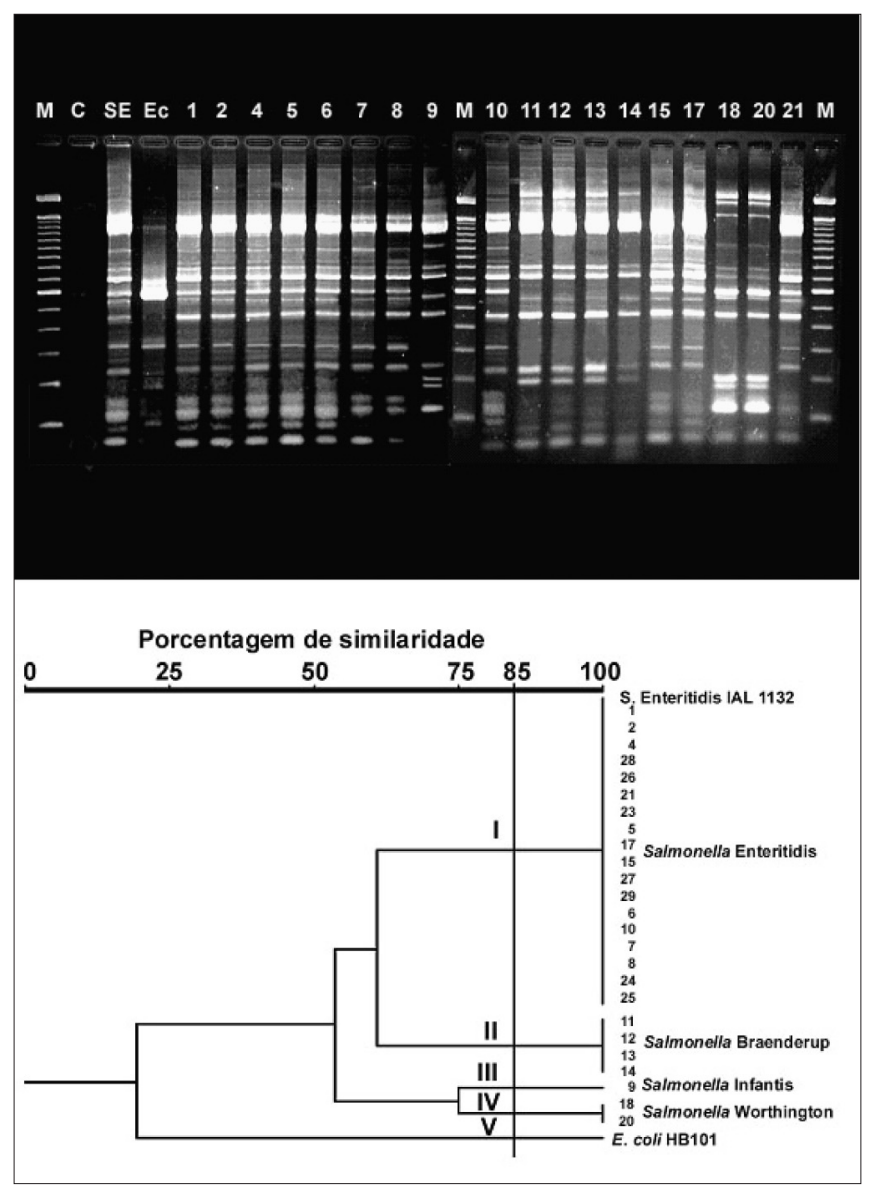

FIGURA 1 - Variabilidade genética de sorovares de Salmonella entérica em isolados de carcaças de frango comercializadas em Londrina entre 1999 e 2000 por REP-PCR. A. Gel representativo dos sorovares de Salmonella entérica. Canaletas M, marcador de peso molecular 100pb; C, água (controle negativo), SE, Salmonella Enteriditis IAL 1132 (controle positivo); Ec, Escherichia coli HB101; 1-2, 4-8, 10, 15, 17, 21, Enteriditis; 9, infantis; 11-14, Braenderup; 18 e 20, Worthington. (Os números corresponden aos códigos das carcaças de frango) $\mathbf{B}$. Dendrograma de similaridade dos sorovares pelo coeficiente Dice. Análise de cluster por unweighted pair group method with the arithmetic averages methods - UPGMA. 
PT4 emergiu associado ao consumo de ovos crus ou não completamente cozidos [26]. Em 1999, 49,0\% das cepas de Salmonella envolvidas em surtos e submetidas à fagotipagem pertenciam a este fagotipo, o qual superou o PT8, historicamente prevalente naquele país [8].

DOS SANTOS, DICKEL \& RODRIGUES [13] e DOS SANTOS et al. [14] fizeram um alerta importante informando que o PT6a está aumentando no Rio Grande do Sul, e que esse fagotipo pode estar desenvolvendo uma estratégia semelhante à atribuída ao PT4, ou seja, adaptação a um determinado ambiente com um potencial diferenciado de patogenicidade para humanos. O fagotipo 6a não foi encontrado neste trabalho, porém, foi encontrado em $7,4 \%$ das amostras de Salmonella Enteriditis envolvidas em surtos ocorridos no Paraná entre 1999 e 2002 [1].

Um aumento do número de fagotipos isolados de frango foi observado durante um estudo de três anos realizado por NUNES et al. [21] em São Paulo (SP). Em 1995, 4 fagotipos diferentes foram identificados, porém, entre 1996 e 1997 o número de fagotipos passou de cinco para oito. Essa constatação indica ser essencial o estudo constante dos fagotipos presentes em aves. Segundo esses mesmos autores, o freqüente isolamento de PT4 em carcaças de frango e o predomínio deste fagotipo na salmonelose humana, sugere uma particular associação entre reservatórios aviários e os surtos de toxiinfecção alimentar no Brasil durante o período de estudo.

Segundo ALCOCER [1], aproximadamente 90,0\% dos surtos de salmonelose ocorridos no Paraná, entre 1999 e 2002, foram causados pelo sorovar Enteriditis e o lisotipo mais prevalente $(86,1 \%)$ foi PT4. Além disso, carne de aves, ovos e derivados foram os principais alimentos responsáveis pelos surtos ocorridos nesse período. As cepas de Salmonella analisadas no presente trabalho foram isoladas de carcaças de frango entre outubro de 1999 e março de 2000. Portanto, a maior relevância deste trabalho foi a constatação de que a carne de frango contaminada pode ser um veículo importante de transmissão de Salmonella e um maior esclarecimento sobre a sua correta manipulação precisa ser realizado para a prevenção da doença.

A combinação de métodos fenotípicos e genotípicos tem sido utilizada na diferenciação de sorovares de Salmonella. No presente trabalho, a REP-PCR forneceu um perfil de bandas único, constante e específico para cada sorovar analisado. O procedimento foi reproduzível e apesar do pequeno número de sorovares testados, parece ser um método atrativo a ser utilizado no futuro para a discriminação preliminar de sorovares de Salmonella.

Muitos autores têm mostrado que tanto a REP como a ERICPCR são métodos genéticos sorovar específico para o gênero Salmonella [4, 20, 30, 34]. A característica sorovar específica da REP-PCR para esse gênero foi relatada por BENNASAR et al. [3], embora utilizando temperatura de anelamento inferior $\left(33^{\circ} \mathrm{C}\right)$ à utilizada no presente trabalho $\left(45^{\circ} \mathrm{C}\right)$.

Outros métodos vêm sendo utilizados na caracterização de Salmonella. WEIGEL et al. [34] mostraram que a eletroforese em gel de pulso alternado (PFGE) é tão discriminativa como a REP-PCR para o gênero Salmonella. Por outro lado, DESAI, THRELFALL \& STANLEY [11] obtiveram bons resultados ao utilizarem a fluorescent amplified-fragment legth polymorphism (FAFLP) para subtipificar Salmonella Enteriditis fagotipo 4. Recentemente, FERNANDES et al. [15] mostraram que a ribotipagem foi capaz de diferenciar seis ribotipos de Enteriditis no fagotipo 8 e três no fagotipo 4 .

O padrão de bandas obtido neste trabalho com a ERIC-PCR produziu um número de bandas inferior ao encontrado na REP-PCR que limitou a discriminação entre os sorovares. Outros primers para ERIC-PCR diferentes dos utilizados neste trabalho mostraram especificidade de padrão de bandas para sorovares de Salmonella [17, 27]. Porém, BURR, JOSEPHSON \& PEPPER [5] afirmaram que a ERIC-PCR não é sorovar específica nem reproduzível.

A maioria dos laboratórios brasileiros realizam a confirmação do isolamento de Salmonella empregando anti-soros polivalentes. Entretanto, para a identificação do sorovar é necessário enviar os isolados para Laboratórios de Referência, devido ao grande número de sorovares e custo dos anti-soros. A combinação da REP-PCR com uma análise computadorizada poderia ser uma ferramenta importante e rápida para a discriminação preliminar dos sorovares de Salmonella mais freqüentemente isolados.

\section{5 - CONCLUSÕES}

Os resultados encontrados neste trabalho confirmaram que a fagotipagem é uma ferramenta útil e discriminativa para o sorovar enteriditis. O fagotipo $4(77,8 \%)$ foi o mais isolado, seguido de PT4a $(11,1)$ e PT7 $(5,6 \%)$.

A REP-PCR forneceu um perfil de bandas único, constante e específico para cada sorovar analisado. O procedimento foi reproduzível e apesar do pequeno número de sorovares testados, parece ser um método atrativo a ser utilizado no futuro para a discriminação preliminar dos sorovares de Salmonella mais freqüentemente isolados.

\section{6 - REFERÊNCIAS BIBLIOGRÁFICAS}

[1] ALCOCER, I. Sorotipagem, fagotipagem, caracterização molecular de cepas de Salmonella spp. e avaliação epidemiológica de surtos ocorridos no Paraná de 1999 a 2004. Londrina, 2004, 218 p. Tese (doutorado em Ciência de Alimentos), Departamento de Tecnologia de Alimentos e Medicamentos, Centro de Ciências Agrárias, Universidade Estadual de Londrina (UEL).

[2] ASSOCIAÇÃO PAULISTA DE AVICULTURA. Estatísticas, 2005. Disponível em: http://www.apa.com. br/estatisticas. Acesso em: 15 de maio de 2005.

[3] BENNASAR, A.; DE LUNA, G.; CABRER, B.; LKALUCAT, J. Rapid identification of Salmonella typhimurium, S. enteriditis and $\mathrm{S}$. vichow isolates by polymerase chain reaction based fingerprinting methods. Int. Microbiol., v. 3, p. 31-38, 2000.

[4] BEYER, W.; MUKENDI, F.M.; KIMMING, P.; BOHM, R. Suitability of repetitive-DNA sequence base PCR fingerprinting for characterizing epidemic isolates 
of Salmonella enteritica serovar Saintpaul. J. Clin. Microbiol., v. 36, n. 6, p. 1.549-1.554, 1998.

[5] BURR, M.D.; JOSEPHSON, K L.; PEPPER, I.L. An evaluation of ERIC-PCR an AP PCR fingerprinting for discriminating Salmonella serotypes. Lett. Appl. Microbiol., v. 27, p. 24-30, 1998.

[6] CANADA COMMUNICABLE DISEASE REPORT. Salmonella enteriditis phage 4 in Ontario Canada Communicable Disease Report, v. 23, December $1^{\text {st }}$, 1997. Disponível em: http://cythera.ic.gc.ca/ dsol;ndis;diseases/salm_e.html. Acesso em: 12 de fevereiro de 2002.

[7] CDC. Salmonella Surveillance Summary, 2003, Atlanta, Georgia: U.S. Department of Health and Human Services, CDC, 2005. Disponível em: http://www.cdc.gov/ncidod/ dbmd/phlisdata/salmtab/2002/Salmonellaannualsummary2003.pdf. Acesso em: 30 de maio de 2005.

[8] CDC-MMWR. Weekly Report, v. 49, n. 4, p. 73-79, 2000. Disponível em: http:/www.cdc.gov/epo/mmwr/ preview/mmwrhtml/mm4904al.htm. Acesso em: 14 de julho de 2004.

[9] COGAN, T.A.; JORGENSEN, F.; LAPPIN-SCOTT, H.M.; BENSON, C.E.; WOODWARD, M.J.; HUMPHREY, T.J. Flagella and curli fimbriae are important for the growth of Salmonella enterica serovars in hen eggs. Microbiol., v. 150, n. 4, p. 1.063-1.071, 2004

[10] COX, J.M. Salmonella enteriditis: virulence factors and invasive infection in poultry. Trends Food Sci. Technol., v. 6, p. 407-410, 1995.

[11] DESAI, M.; THRELFALL, E.J.; STANLEY, J. Fluorescent amplified-fragment length polymorphism subtyping of the Salmonella enterica serovar enteriditis phage type 4 clone complex. J. Clin. Microbiol., v. 39, n. 1, p. 201-206, 2001.

[12] DIMRI, G.P.; RUDD, K.E.; MORGAN, M.K.; BAYAT, H.; AMES, F.F.L. Physical mapping of repetitive extragenic palindromic sequences in Escherichia coli and phylogenetic distribution among Escherichia coli strains and other enteric bacteria. J. Bacteriol., v. 174, n. 4, p. 4.583-4.593, 1992.

[13] DOS SANTOS, L.R.; DICKEL, E.L.; RODRIGUES, L.B. Identificação de Salmonella enteriditis fagotipo $6 \mathrm{a} \mathrm{em}$ amostras de alimentos, humanos e materiais de origem avícola. Hig. Aliment., v. 18, n. 119, p. 64-67, 2004.

[14] DOS SANTOS, L.R.; DO NASCIMENTO, V.P.; DE OLIVEIRA, S.D.; RODRIGUES, D.P; DOS REIS, E.M.; SEKI, L.M.; RIBEIRO, A.R.; FERNANDES, S.A. Phage types of Salmonella enteriditis isolated from clinical and food samples, and from broiler carcasses in southern Brazil, Rev. Inst. Med. Trop. S. Paulo, v. 45, n. 1, p. 1-4, 2003.

[15] FERNANDES, S.A.; GHILARDI, A.C.R.; TAVECHIO, A.T.; MACHADO, A.M.O.; PIGNATARI, A.C.C. Phenotypic and molecular characterization of Salmonella enteriditis strains isolated in São Paulo, Brazil, Rev. Inst. Med. Trop. S. Paulo, v. 45, n. 2, p. 59-63, 2003.

[16] HEALTH PROTECTION AGENCY, 2004 The changing epidemiology of Salmonella enteriditis infection in England \& Wales. Disponível em: http://www.phls. co.uk/infections/topics_az/salmonella/se_update.html. Acesso em: 30 de maio de 2005.

[17] JONHSON, J.; CLABOTS, C.; AZAR, M.; BOXRUD, D.J.; BESSER J.M.; THURN, J.R. Molecular analysis of a hospital cafeteria-associated salmonellosis outbreak using modified repetitive element PCR fingerprinting. J. Clin. Microbiol., v. 39, n. 10, p. 3.452-3.460, 2001.

[18] KIMURA, A.C.; REDDY, V.; MARCUS, R.; CIESLAK, P.R.; MOHLE-BOETANI, J.C.; KASSENBORG, H.D.; SEGLER, S.D.; HARDNETT, F.P.; BARRETT, T.; SWERDLOW, D.L. Emerging Infections Program FoodNet Working Group. Chicken consumption is a newly identified risk factor for sporadic Salmonella enterica serotype enteriditis infections in the United States: a case-control study in FoodNet sites. Clin. Infect. Dis., v. 38, suppl 3, p. 244-252. 2004.

[19] LÓPEZ-MOLINA, N.; LACONCHA, I.; REMENTERIA, A.; AUDICANA, A.; REALES, I.; GARIZAR, J. Typhing of Salmonella enteriditis of different phage types of PCR fingerprinting. J. Appl. Microbiol., v. 84, p. 877882, 1998.

[20] MACIOROWSKI, K.G.; PILLAI, S.D.; JONES, F.T.; RICKE, S.C. Polymerase chain reaction detection of foodborne Salmonella spp. in animal feeds. Crit. Rev. Microbiol., v. 31, n. 1, p. 45-53, 2005.

[21] NUNES, I.A.; HELMUTH, R.; SCHROETER, A.; MEAD, G.G.; SANTOS, M.A.A.; SOLARI, C.A.; SILVA, O.R.; FERREIRA, A.J.P. Phage typing of Salmonella enteriditis form different sources in Brazil. J. Food Prot., v. 66, n 2, p. 324-327, 2003.

[22] PERESI, J.T.; ALMEIDA, I.A.Z.C.; LIMA, S.I.; MARQUES, D.F.; RODRIGUES, E.C.A.; FERNANDES, S.A.; GELLI, D.S.; IRINO, K. Surtos de enfermidades transmitidas por alimentos causados por Salmonella enteriditis. Rev. Saúde Pública, v. 32, n. 5, p. 477-483, 1998.

[23] PHLS Salmonella infections, England and Wales: reports to the (Salmonella data set). CDR Wkly, v. 6, n. 47, 1996.

[24] POPOFF, M. Antigenic formulas of the Salmonella serovars. $8^{\text {th }}$ ed. Paris: WHO Collaborating Centre for Reference and Research on Salmonella, 2001.

[25] SILVA, E.N.; DUARTE, A. Salmonella enteriditis em aves: retrospectiva no Brasil. Rev. Bras. Ciênc. Avíc., v. 4, n. 2, p. 85-100, 2002.

[26] SOBEL, J; HIRSHFELD, A.B.; MCTIGUE, K.; BURNETT, C.L.; ALTEKRUSE, S.; BRENNER, F.; MALCOLM, G.; MOTTICE, S.L.; NICHOLS, C.R.; SWERDLOW, D.L. The pandemic of Salmonella enteriditis phage type 4 reaches Utah: a complex investigation confirms the need for continuing rigorous control measures. Epidemiol. Infec., v. 125, n. 1, p. 1-8, 2000.

[27] SWANENBURG, M.; URLINGS, H.A.P; KEUZENKAMP, D.A.; SNIJDERS, J.M.A. Validation of ERIC-PCR as a tool in epidemiology research of Salmonella in slaughter pigs. J. Ind. Microbiol. Biotechn., v. 21, p. 141-144, 1998

[28] TYLER, F.D.; WANG, G.; TYLER, S. D.; JOHNSON, W. M. Guest commentary. Factors affecting reliability and reproducibility of amplification-based DNA fingerprinting of representative bacterial pathogens. J. Clin. Microbiol., v. 35, n. 2, p. 339-346, 1997.

[29] UNIÃO BRASILEIRA DE AVICULTURA. Relatório anual 2004. Brasília: UBA, 2004.

[30] VERSALOVIC, J.; KOEUTH, T.; LUPSKI, J.R. Genomic fingerprinting of bacteria using repetitive sequencebased polymerase chain reaction, Methods Mol. Cell. Biol., v. 5, p. 25-40, 1994.

[31] VERSALOVIC, J.; KOEUTH. T.; LUPSKI, J.R. Distribution of repetitive DNA sequences in eubacteria and 
application to fingerprinting of bacterial genomes. Nucl. Acids Res., v. 19, p. 6.823-6.831, 1991.

[32] WARD L.R.; THRELFALL, J.; SMITH, H.R.; O'BRIEN S.J.; RIEMANN, H.; KASS, M.; CLIVER, R. Salmonella enteriditis Epidemic. Science, v. 287, p. 1.753, March $10^{\text {th }}, 2000$ (in Letters).

[33] WARD, L.R.; DE SA, J.D.H.; ROWE, B. A phage-typing scheme for Salmonella enteriditis. Epidemiol. Infec., v. 99, p. 291-294, 1987.

[34] WEIGEL, R.M.; QIAO, B.; TEFEREDEGNE, B.; SUH, D.K.; BARBER, D.A.; ISAACSON, R.E.; WHITE, B.A. Comparison of pulsed field gel electrophoresis and repetitive sequence polymerase chain reaction as genotyping methods for detection of genetic diversity and inferring transmission of Salmonella. Vet. Microbiol., v. 100, n. 3-4, p. 205-217, 2004.

[35] WHO - WORLD HEALTH ORGANIZATION - [on-line] Global epidemic detection an response. Disponível em: http://www.who.int/emc/surveill/index.html. Acesso em: 12 de dezembro de 2002.

[36] WHO, 2004. [on-line]. Global Salm-Surv. Disponível em: http://www.who.int/entity/salmsurv/activities/ databank/en. Acesso em: 14 maio de 2005.

\section{7 - AGRADECIMENTOS}

À Coordenação de Aperfeiçoamento de Pessoal de Nível Superior (Capes) pela bolsa PEC/PG de doutorado concedida à Iliana Alcocer. À Doutora Dalia dos Prazeres Rodrigues por possibilitar a realização da sorotipagem e fagotipagem dos isolados de Salmonella no Laboratório de Enterobactérias do Departamento de Bacteriologia do Instituto Oswaldo Cruz - Fiocruz, Rio de Janeiro. 